\title{
RECEPTORES IMAGINADOS: OS SENTIDOS DO POPULAR ${ }^{1}$
}

Imagined receptors: The senses of the popular

Maria Salett Tauk Santos ${ }^{2}$

\begin{abstract}
Resumo
O texto apresenta, de forma resumida, os resultados de uma pesquisa empírica sobre os sentidos do popular. A partir da abordagem teórica sobre as culturas populares, na perspectiva dos estudos culturais contemporâneos, partiu-se para um estudo que analisa os sentidos do popular em segmentos que, pela atividade laboral, estão na condição de popular ou mantêm alguma relação ou compromisso com este. $\mathrm{O}$ confronto entre os aportes teóricos e os sentidos que o popular adquire nos domínios do empírico demonstra algumas coincidências: o caráter de desigualdade como operam as culturas populares. Entretanto, revela um certo descompasso: o empírico conceitua o popular na relação cultura hegemônica, culturas populares; a teoria avança para compreender o popular contemporâneo nos processos de hibridização, explosão e dispersão de referências culturais.
\end{abstract}

Palavras-chave: culturas populares, estudos culturais, recepção, hibridização cultural.

\begin{abstract}
The text presents, in a simple form, the results of an empirical research about the senses of the popular. Starting from a theoric approach about popular cultures, in the perspective of cultural contemporary studies, it passed to a study that analyses the senses of the popular senses in segments that, by labor activity, are in a popular condition or maintain some relationship or compromise with it. The confrontation between the theoric supports and the senses that the popular acquire in empirics domains demonstrates some coincidences: the unequal character in which popular cultures function. However it reveals a certain unbalance: the empiric conceives the popular in the relationship with hegemonic culture, popular cultures; the theory advances to understand contemporary popular in the processes of hybridization, explosion and dispersion of cultural references.
\end{abstract}

\footnotetext{
${ }^{1}$ Trabalho apresentado ao Grupo de Trabalho "Recepção, usos e consumo midiáticos" do XVII Encontro da Compos, na UNIP, São Paulo, SP, em junho de 2008.

${ }^{2}$ Doutora em Ciências da Comunicação pela ECA/USP. Professora do Programa de Pós-Graduação em Extensão Rural e Desenvolvimento Local - Posmex da Universidade Federal Rural de Pernambuco. E-mail : mstauk@terra.com.br
} 
Key words: popular cultures, cultural studies, reception, cultural hybridization.

\section{Resumen}

El texto presenta, en forma resumida, los resultados de una investigación empírica sobre los sentidos de lo popular. Desde el enfoque teórico sobre las culturas populares, en la perspectiva de los estudios culturales contemporáneos, se partió para un estudio que analiza el significado de los sectores populares en los que, por la actividad laboral, están en la condición de popular o mantienen alguna relación o compromiso con este. El enfrentamiento entre las contribuciones teóricas y los sentidos que lo popular adquiere en los dominios de lo empírico demuestra algunas coincidencias: el carácter de desigualdad como operan las culturas populares. Mientras tanto, revela un cierto desequilibrio: lo empírico concibe lo popular en la relación con la cultura hegemónica, culturas populares; la teoría avanza para entender el popular contemporáneo en los procesos de hibridación, explosión y dispersión de las referencias culturales.

Palabras clave: culturas populares, los estudios culturales, la recepción, la hibridación cultural.

O objetivo deste estudo é analisar os sentidos do popular na contemporaneidade, abordando a polissemia que o termo adquire em diferentes segmentos de produtores de bens e mensagens voltados às culturas populares, como temática de trabalho.

O que se pretende é, através de um estudo exploratório, cotejar, no empírico, os sentidos atribuídos ao popular por pessoas que pela atividade laboral se situam na condição de popular; cujo trabalho volta-se para o popular; aquele que sendo popular tem o trabalho voltado para o não popular; os que não sendo popular mas que produzem mensagens para os contextos populares; ou ainda o que não sendo popular adota o popular como temática do trabalho que desenvolvem.

O interesse em conhecer os sentidos atribuídos ao popular, ou aqueles que o popular se atribui em contextos empíricos, se deve ao entendimento de que avançamos muito na compreensão teórica do popular, nos estudos de comunicação imbricados à cultura na perspectiva dos estudos culturais. Embora esses estudos não possam ser reduzidos ao estudo da cultura popular, como assinala Escosteguy (2001), a temática do popular é central nesses estudos. Apesar desse avanço, podemos considerar, entretanto, como válida ainda nos dias atuais a observação de Raymond Willams de que "a cultura popular não foi identificada pelo povo, mas por outros” (Willams 1983 apud Escosreguy 2001: 107). Significa dizer que o que sabemos do popular é o resultado de construções teóricoacadêmicas sobre as culturas populares, entretanto seguimos conhecendo muito pouco sua 
realidade e o que pensam as culturas populares sobre si mesmas ou como os setores não populares representam o popular. Desconhecemos igualmente se os estatutos teóricos e acadêmicos erigidos sobre o popular coincidem ou exercem alguma influência nos sentidos empíricos atribuídos ao popular.

O itinerário teórico metodológico que norteia a pesquisa são os Estudos Culturais nas atualizações do pensamento gramsciano, via aportes de Jesus Martin-Barbero e Néstor García Canclini. Perspectiva teórica com a qual vimos trabalhando há quase vinte anos, aplicada a estudos de recepção em contextos populares ${ }^{3}$.

Compreender os sentidos do popular contemporâneo implica abandonar conceitos que consideram as culturas populares como essência pura, expressão da personalidade de um povo ou, como na abordagem dos estudos do folclore, um conjunto de tradições ou de essências e ideais preservados (García Canclini 1983).

A compreensão teórica do popular contemporâneo via estudos culturais começa a ser construída a partir do pensamento de Antonio Gramsci, expresso nos volumes dos seus Cadernos do Cárcere, que tratam do popular. Em suas reflexões sobre os cantos populares Gramsci classifica-os em

1. Cantos compostos pelo povo e para o povo; 2. Cantos que não são compostos pelo povo e sim para ele; 3. Cantos que não são compostos para o povo nem para o povo, mas que o povo se apropria porque são coerentes com o seu modo de sentir e de pensar (Gramsci 1978: 190).

Para Gramsci, todos os cantos populares pertencem a esta última categoria porque o que distingue o canto popular não é o fato artístico, nem a sua origem histórica, senão o modo como esses cantos concebem o mundo e a vida (Gonzalez

\footnotetext{
${ }^{3}$ A esse respeito ver: TAUK SANTOS, M. Salett. Inclusão digital, inclusão social: as culturas populares em rede. Recife : Bagaço. 2008 (no prelo). TAUK SANTOS, M. Salett. Cooperativismo no desenvolvimento local: a recepção popular da Incubadora Tecnológica de Cooperativas da Universidade Federal Rural de Pernambuco, in Associativismo e desenvolvimento local/organizadores Maria Salett Tauk Santos e Ângelo Brás Fernandes Callou. Recife : Bagaço. 2006, p. 33-68. TAUK SANTOS, M. Salett e NASCI-MENTO, MARTA R. Desvendando o mapa noturno: análise da perspectiva das mediações nos estudos de recepção, in: Recepção midiática e espaço público: novos olhares/Mauro Wilton (org). São Paulo: Paulinas, 2006. TAUK SANTOS, M. Salett e LIMA, Conceição M. D. Desafios cooperativos e estratégias de comunicação das incubadoras cooperativas populares, in: Revista Unircoop - Rede universitária das Américas em estudos cooperativos e associativismo. Vol. 4, $\mathrm{n}^{\circ}$. 1, out. 2006. Sherbrooke : IRECUS, Universidade de Sherbrooke, CA. TAUK SANTOS, M. Salett. Políticas de comunicação para o desenvolvi-mento local: estudo de recepção da proposta de gestão participativa da Prefeitura de Camaragibe, PE, in Anais do XXVI Congresso Brasileiro de Ciências da Comunicação. Belo Horizonte, 2003. TAUK SANTOS, M. Salett . $O$ consumo de bens culturais nas culturas populares: identidade recorvertida ou diversidade refuncionalizada? In: Comunicação e Multiculturalismo (Organização: Cicília Ma . K. Peruzzo e J.B.Pinho). São Paulo : Intercom; Manaus : Univ. Fed. do Amazonas, 2001. TAUK SANTOS, M. Salett. Quando a violência faz parte do contrato: estudo de recepção da Folha de Pernambuco, in: Anais do XXIII Congresso Brasileiro de Ciências da Comunicação. Manaus, 2000. TAUK SANTOS, M. Salett. Comunicação e consumo: espaço das mediações da cultura massiva e das culturas populares, in: Intercom Revista Brasileira de Comunicação, São Paulo, vol. XIX, nº. 2, jul/dez, 1996. p. 35-48
} 
1990).

Para Cirese, portanto, “a popularidade deve ser estabelecida como fato e não como essência, como posição relacional e não substancia" (Cirese apud Canclini 1988: 41).

Nessa perspectiva informa García Canclini:

\begin{abstract}
O popular não deve por nós ser apontado como um conjunto de objetos (peças de artesanato ou danças indígenas), mas sim como uma posição e uma prática. Ele não pode ser fixado num tipo particular de produtos e mensagens, porque o sentido de ambos é constantemente alterado pelos conflitos sociais. Nenhum objeto tem o seu caráter popular garantido para sempre porque foi produzido pelo povo ou porque o consome com avidez; o sentido e o valor populares vão sendo conquistados nas relações sociais. É o uso e não a origem, a posição e a capacidade de suscitar práticas ou representações populares, que confere essa identidade. (García Canclini 1983: 135).
\end{abstract}

Do aporte de Gramsci vão sendo construídas as idéias matrizes que vão dar os sentidos do popular contemporâneo, a partir dos anos de 1980:

- A compreensão da desigualdade e da subalternidade a que o popular acha-se submetido em uma sociedade de classes:

As culturas populares existem porque a reprodução desigual da sociedade gera uma apropriação desigual da sociedade gera uma apropriação desigual dos bens econômicos e culturais por parte de diferentes classes e grupos na produção e no consumo; uma elaboração própria de suas condições de vida e uma satisfação específica de suas necessidades nos setores excluídos da participação plena no produto social; uma interação conflitiva entre as classes populares com as hegemônicas pela apropriação dos bens (García Canclini 1987: 49).

- A noção do popular enquanto subalterno, numa ordem de hegemonia frente à

qual as culturas populares emprestam consenso, mas mantêm em relação a esta uma certa autonomia no que se refere à percepção da realidade e adoção de valores:

se não pensarmos no povo como uma massa submissa que se deixa iludir sempre a respeito do que quer admitiremos que sua dependência se deve em parte, a que encontra na ação hegemônica algo útil para as suas necessidades. Devido ao fato de que este benefício não é inteiramente ilusório, as classes populares emprestam o seu consenso, concedem à hegemonia uma certa legitimidade (García Canclini 1988: 24).

- A abordagem do caráter conflitivo e de classe das culturas populares:

a questão decisiva consiste na compreensão das culturas populares através da sua conexão com os conflitos de classe e com as condições de exploração sob as quais estes setores produzem e consomem (García Canclini 1983: 43).

Com as mudanças sócio-culturais decorrentes dos processos da globalização, a perspectiva de pensar as culturas populares de forma relacional à cultura hegemônica, mediatizadas pela noção de classe, cede lugar a uma abordagem considerando-as em 
processo de hibridização com a cultura massiva e as suas relações com o consumo. A relação cultura hegemônica/culturas populares já não dá mais para interpretar a desigualdade a que vivem submetidas as culturas populares contemporâneas, considerando, como assinala Canclini, que já não se impõe uma cultura homogênea:

los nuevos riesgos son la abundancia dispersa y la concentración asfixiante. Coincido con Jean-Pierre Warnier: el problema que enfrentan las sociedades contemporâneas es más de explosión y dispersión de las referencias culturales, que de homogeneización (García Canclini 2004: 23).

Em conseqüência disso, "o popular se reformula como uma posição múltipla, representativa de correntes culturais diversas que reivindicam uma inter-comunicação massiva permanente" (Escoteguy 2001: 117). O popular não aparece mais como oposto ao massivo, mas como um modo de atuar nele (Canclini 1987 apud Escoteguy 2001:117).

A principal conseqüência da incorporação das massas ao estudo da cultura é, como assinala Martin-Barbero, a dissolução-superação das classes sociais como poder explicativo das desigualdades das culturas populares. Nessa perspectiva, para se compreender o popular contemporâneo é necessário, como recomenda o autor,

incluir no estudo do popular não só aquilo que culturalmente produzem as massas, mas também o que consomem, aquilo de que se alimentam; e a de pensar o popular na cultura não como algo limitado ao que se relaciona com o seu passado, mas também e principalmente o popular ligado à modernidade, à mestiçagem e à complexidade do urbano (Martin-Barbero 1987: 56).

Ao considerar o consumo como um dos espaços importantes onde se constituem as culturas populares, Canclini o situa em um processo ambivalente. De um lado considera que é no âmbito do consumo que se dá “o conflito originado pela participação desigual na estrutura produtiva, conflito que se prolonga na distribuição dos bens e na satisfação das necessidades" (Canclini 1988: 52). O sentido do consumo seria o da distinção, particularmente no domínio do simbólico, segundo a teoria de Pierre Bourdieu.

Por outro lado, Canclini observa que o consumo não constitui apenas um elemento de distinção, ele funciona igualmente como fator de integração, na medida em que não tem por finalidade apenas a posse de um objeto ou satisfação de uma necessidade, mas também o de definir valores comuns:

em tempo de fraturas e heterogeneidade, de comunicações fluidas das ordens transnacionais da informação, da moda e do saber..., encontrarmos códigos que nos unificam. Porém esses códigos compartilhados são cada vez menos o da etnia, ou da nação onde nascemos... Uma nação se define menos, a essa altura, por seus limites territoriais... Mas, sobrevive como uma comunidade hermenêutica de consumidores cujos hábitos tradicionais levam-na a relacionar-se de um modo peculiar com objetos e informações circulantes nas redes internacionais (Canclini 1995). 
Ao transitarem em um mundo em que o consumo se tornou o espaço da modernidade, o lugar da objetivação dos desejos, da reprodução da força de trabalho e do acesso ao exercício da cidadania, as culturas populares tornam-se sujeitos de um processo de hibridização.

A hibridização deriva de "processos sócio-culturais nos quais estruturas ou práticas discretas, que existiam de forma separada, se combinam para gerar novas estruturas, objetos e práticas" (Canclini 1990: XIX). Um dos fenômenos através dos quais a hibridização se manifesta, e que constitui o mais recorrente nas culturas populares, é a reconversão cultural $^{4}$ Ela pode ocorrer de modo não planejado, como resultado de processos migratórios, turísticos ou de intercâmbio comunicacional ou econômico. Entretanto, freqüentemente ela surge da intenção deliberada de reconverter um código cultural, pré-existente, em novas condições de produção e mercado (Canclini: 1996).

Canclini, em seu estudo sobre as culturas híbridas, demonstra como as culturas populares realizam a reconversão cultural:

los migrantes campesinos que adaptan sus saberes para trabajar y consumir em la ciudad y sus artesanias para interessar a compradores urbanos; los obreros que reformulam su cultura laboral ante las nuevas tecnologias productivas; los movimientos indígenas que rensertan sus demandas en la politica transnacional o en um discurso ecológico, y aprenden a comunicarlas por radio y television (Canclini 1996: 3 ).

Para Canclini, o termo hibridização é o mais adequado para significar processos de relações a que estão submetidas as culturas populares contemporâneas. Muito mais que sincretismos, que se refere a combinações de práticas religiosas tradicionais; mestiçagem, que diz respeito à fusão entre povos e culturas desses povos; e crioulização, que trata de misturas interculturais que envolvem a língua, "a palavra hibridização aparece mais dúctil para nomear não só as combinações de elementos étnicos ou religiosos, mas também a de produtos das tecnologias avançadas e processos sociais modernos ou pós-modernos" (Canclini 1996: 8).

\footnotetext{
${ }^{4}$ Alguns estudos empíricos sobre reconversão cultural nas culturas populares: TAUK SANTOS, M. Salett. Comunicação rural -velho objeto, nova abordagem: mediação, reconversão cultural e desenvolvimento local, in: LOPES, M. Immacolata V.de, FRAU-MEIGS, D.e TAUK SANTOS, M. Salett. (orgs.) Comunicação e informação: identidades e fronteiras. São Paulo: Intercom; Recife: Bagaço, 2000 p.291-301; TAUK SANTOS, M. SALETT.O consumo de bens culturais nas culturas populares:identidade reconvertida ou diversidade refuncionalizada? In: PERUZZO, Cicília e PINHO, J. B. (orgs.) Comunicação e multiculturalismo. São Paulo: Intercom;Manaus:UFAM, 2001 p. 253 - 275. CUNHA, Theresa Sampaio. É festa em Surubim é dia de vaquejada: estudo das reconversões culturais da vaquejada na sua comunicação com a cultura massiva. (Dissertação de mestrado). Recife: CMARCR -UFRPE, 2003; SILVA, José Carlos de Melo. Culturas populares, hibridização e novas ruralidades: reconversões culturais na cerâmica figurativa do Alto do Moura, Caruaru, Pernambuco.( Dissertação) Mestrado em Extensão Rural e Desenvolvimento Local. Recife: UFRPE,2007
} 
Mesmo admitindo a assertiva de Canclini (1996: 9) de que "a hibridização interessa tanto aos setores hegemônicos quanto aos populares, que querem apropriar-se dos benefícios da modernidade", é necessário compreender que as reconversões que realizam as culturas populares, em relação à cultura massiva, não se dão de forma natural ou espontânea. Reconverter os códigos da sua cultura em outra, com a intenção de se inserir no mercado de trabalho, participar de uma ordem social ou simplesmente ser reconhecido, representa em muitos casos uma experiência penosa e difícil para as culturas populares. A explicação está no fato de que "a principal característica dos contextos populares é a contingência, ou seja, o acesso aos bens materiais e imateriais se dá de forma incompleta, desigual ou desnivelada" (Tauk Santos 2001).

O aporte do popular enquanto cultura híbrida é útil para compreender como, através das mesclas de assimilações e conflitos, a hibridização cultural segue engendrando a pósmodernidade latino-americana, pois de um lado representa a persistência de costumes, pensamentos antigos, como resultado do acesso desigual das culturas populares à modernidade; por outro lado, como afirma Canclini, "essas hibridizações persistem porque são fecundas ao combinar a iconografia pré-colombiana e o geometrismo contemporâneo; entre a cultura visual e musical de elites, a popular prémassiva e a das indústrias comunicacionais" (García Canclini 1996: 2).

\section{ESTRATÉGIA METODOLÓGICA}

Mais do que a busca das lógicas que sustentam o popular, privilegiou-se a pesquisa do popular a partir das lógicas que sustentam as práticas culturais, como propõe MartinBarbero (1995), as lógicas do campo cultural vivido.

Nessa perspectiva, a partir desse itinerário teórico de abordagem dos sentidos polissêmicos e complexos do popular, partiu-se para o cotejamento de segmentos que pela atividade laboral estivessem incluídos em uma das quatro categorias identificadas para dar conta dos sentidos do popular ${ }^{5}$ a) o popular voltado ou que trabalha para o popular, nessa categoria foram entrevistados os mercadores de mercados públicos; b) o popular que trabalha para o massivo ou em conexão com este. Os representantes dessa categoria foram os artistas populares Selma do Coco, Arlindo dos Oito Baixos e Mestre Afonso; c) o não popular, mas cujo trabalho volta-se para os contextos populares, a exemplo dos repórteres televisivos que atuam em jornalismo esportivo ou comunitário; d) finalmente, o não

\footnotetext{
${ }^{5}$ Participaram da construção do instrumento e da coleta de dados da pesquisa, os alunos da turma de 2006 do Programa de Pós-Graduação em Extensão Rural e Desenvolvimento Local da UFRPE, no âmbito da disciplina Comunicação e Culturas Populares, sob a coordenação da Prof. Dra. Maria Salett Tauk Santos.
} 
popular, cujo trabalho não se volta para o popular, mas que adota o popular como temática do seu trabalho. Foram escolhidos como representantes dessa categoria um compositor de frevo, o maestro Spok, o escritor Ariano Suassuna e o pesquisador e folclorista Roberto Benjamin.

A intenção da pesquisa, nesta fase, é de uma abordagem compreensiva dos sentidos do popular nestes segmentos, deixando a preocupação com a causalidade do fenômeno para uma etapa posterior. Nessa perspectiva, foi construído um roteiro para entrevista semiestruturada dividida em três blocos. No primeiro bloco, composto por oito perguntas abertas, perguntou-se aos entrevistados como definiam, localizavam, reconheciam o popular em relação a sujeitos e objetos. Além disso, perguntou-se sobre onde localizavam o popular na atividade que desenvolviam; a importância deste para o seu trabalho; e sobre o que consideravam um tema popular na política, na arte e na mídia.

No segundo bloco foi solicitado aos entrevistados que definissem, justificando, o que consideravam uma pessoa popular, um objeto popular, um acontecimento popular, um lugar popular e uma idéia popular. No terceiro pediu-se ao entrevistado um depoimento sobre como surgiu a opção, a temática e ou o compromisso com o popular no seu trabalho.

\section{O POPULAR PELO POPULAR}

Para os trabalhadores dos mercados públicos entrevistados ${ }^{6}$, o popular é visto como estatuto, quando se referem a coisas populares como "coisa do dia-a-dia", "coisa de menor valor", "o que é barato". Nesse sentido localizam o popular "nas feiras livres", nos "camelôs", "mercados públicos", "periferias" e nos "transportes coletivos".

Em relação às pessoas, os atributos igualmente é o de ser popular pelo "baixo poder aquisitivo", pelo "modo de calar", o "modo de vestir", a "humildade" a "simpatia" e a "alegria".

Consideram o seu trabalho popular pelos usos: destinam-se a uma "clientela popular", “comercializa produtos populares", “a preços populares”. Atribuem a si próprios a condição de popular pelo fato de "tratarem sempre os clientes como amigos" e "nunca deixá-los insatisfeitos".

Quanto aos objetos, lugares e acontecimentos, os mercadores os consideram populares a partir de critérios dos usos. Os objetos mencionados foram: ratoeira, fogão, televisão, celular e bola de futebol. Como lugares populares destacaram a praia e o mercado público. Entre os acontecimentos populares apareceram o natal, o carnaval e a festa do

\footnotetext{
${ }^{6}$ Entrevistas concedidas aos mestrandos Ana Clara C. Lima, Gentil Vicente e Rosa Maria Saraiva.
} 
próprio mercado.

Quando indagados sobre uma idéia popular, mais uma vez é o sentido dos usos que predomina na noção do popular para os mercadores, quando mencionam o futebol, a propaganda boca-a-boca e a caninha 51.

\section{DO POPULAR AO MASSIVO}

Neste segmento foram entrevistados ${ }^{7}$ uma cantora e compositora de coco, Selma do Coco; um sanfoneiro de oito baixos, Arlindo dos Oito Baixos; e Mestre Afonso, presidente do Maracatu Leão Coroado de Pernambuco.

Os sentidos do popular para esses artistas estão ligados desde aos atributos pessoais como "pessoa que trabalha em qualquer canto e bem à vontade" e que "se dá com todo mundo" à idéia do popular como estatuto, atribuído à condição de pobreza: "popular é aquilo que a gente pode botar dentro da comunidade e fazer aquilo mais simples, porque popular é coisa de gente pobre" (Mestre Afonso).

Há ainda a compreensão do popular associado à raiz cultural, à tradição, conforme o pensamento de Mestre Afonso: “eu não olho o lado artístico, eu olho o lado da tradição e a segurança das nossas raízes... esse negócio de ser artista não me interessa. Eu prefiro manter a minha tradição, cultivar as bases religiosas que estão dentro da nossa cultura”.

Entre os sentidos atribuídos ao popular, pelos artistas populares, aparece o da resistência política, do popular enquanto classe: “o meu trabalho é popular. Hoje já está ficando assim: as pessoas de classe média alta, o pessoal da elite já está querendo se apoderar, então o maracatu já está deixando de ser popular. Não é mais do povo" (Mestre Afonso).

\section{DO MASSIVO AO POPULAR}

$\mathrm{Na}$ categoria de produtores de mensagens, destinadas às audiências populares, foram entrevistados ${ }^{8}$ três jornalistas de três emissoras de televisão de Pernambuco: Mônica Silveira, da TV Globo; Mônica Carvalho, da TV Jornal; e Evaristo Filho, da TV Globo.

Há um esforço teórico na compreensão dos repórteres televisivos a respeito do que significa o popular, distinguindo o popular relacionado à cultura popular, do popular que “diz respeito ao povo ou está acessível a todos" (Silveira). Os sentidos do popular, portanto, se aproximam à noção ora de estatuto, de origem, ora relacionado à categoria de classe e

\footnotetext{
${ }_{8}^{7}$ Dados extraídos das entrevistas concedidas aos mestrandos Floriano Quaresma e Nelson Varela.

${ }^{8}$ Dados das entrevistas realizadas pelos mestrandos Gilvanice Marques e Marcílio José.
} 
aos usos.

A noção do popular enquanto classe social aparece no depoimento dos entrevistados quando afirmam o caráter popular do seu trabalho: "as mensagens são direcionadas para o interesse das classes populares" (Carvalho). Ou quando negam a condição popular do seu trabalho: "por mais esforço que haja na elaboração de um trabalho pretendendo ser popular, isso não avalia o meu trabalho como popular" (Silveira).

O popular como estatuto de classe aparece também na localização do "gosto popular", representado no jornalismo na TV: "podemos ver o popular no texto, na escolha das imagens. Falar de catástrofe é sempre um ingrediente popular dentro do telejornal" (Silveira).

Sobre a importância do popular no trabalho de jornalismo na TV, os sentidos do popular, para os entrevistados, aparecem ora vinculado à noção de compromisso: "a gente tenta passar as informações mais relevantes para torná-los mais informados" (Carvalho); ora vinculado à noção de uso, o popular associado ao massivo: "na prestação de serviços que interessam a todos" (E. Filho); ou ainda através de uma visão idílica ou idealizada do popular: “o popular dá cara, alma e cor ao que é notícia” (Carvalho).

\section{O POPULAR COMO TEMÁTICA DE TRABALHO}

Neste segmento foram entrevistados o escritor Ariano Suassuna, o pesquisador e folclorista Roberto Benjamin e o Maestro Spok. Os três têm em comum o fato de abordar o popular como temática na produção literária e musical.

Prevalece entre os escritores a compreensão do popular enquanto classe social: "no Brasil eu acho que arte popular e cultura popular são a arte feita pela imensa maioria de despossuídos que constitui em nosso país o quarto estado" (A. Suassuna).

Ou na relação de classes, ressaltando a desigualdade a que são submetidas as classes populares: "a definição do popular é a partir do sentido da existência de diferença nas classes sociais, o popular é a princípio a produção das classes populares, das classes inferiores da sociedade" (R. Benjamin).

Ou ainda, o popular como estatuto político de classe: "Machado de Assis dizia que no Brasil existem dois países diferentes: um país oficial e um país real. Todos nós hoje pertencemos à classe privilegiada, somos integrantes do Brasil oficial, o popular se localiza no povo do Brasil real" (A. Suassuna).

Os sentidos do popular aparecem também como origem, como território e como identidade, associados a zonas periféricas das camadas sociais desfavorecidas: "o popular 
para mim é onde eu nasci e cresci. Eu me refiro ao popular como tudo o que você possa imaginar que fez parte da minha vida e que fez parte do lugar que eu vivo e das coisas que faço e escuto. Eu nasci em Igarasssu e me criei em Abreu e Lima"” (Spok).

O popular igualmente é associado à tradição, ao que é considerado genuíno: "o que eu imagino do popular é tudo o que ouvi dos mestres que meu pai colocava para eu ouvir: Nelson Ferreira, Alevino, Claudionor Germano, os poetas e cantadores que moram perto da minha casa" (Spok).

O sentido do popular, como estatuto dos setores desfavorecidos e subalternos, prevalece quando os entrevistados localizam os seus trabalhos frente às culturas populares:

\begin{abstract}
"quando dizem que meu "Auto da Compadecida" é uma peça popular, eu discordo, não que eu tenha desprezo pelo popular, mas é uma peça ligada ao popular, eu parti de três folhetos de cordel, que são integrantes da cultura popular. Mas o meu teatro não é arte popular porque eu, por formação, nasci, me criei e me formei na classe privilegiada" (A Suassuna).

"Meu trabalho é uma reflexão sobre o popular. É uma coleta, uma sistematização, uma reflexão sobre o mundo popular. Pela minha própria formação eu não seria popular” (R. Bejmain ).

"O trabalho que a gente faz não atinge popularmente o povão. Atinge mais um público especializado que aprecia festival de jazz” (Spok).
\end{abstract}

\title{
6. CONSIDERAÇÕES FINAIS
}

Apesar do caráter incompleto das análises, considerando a riqueza dos dados coletados, os depoimentos permitem, entretanto, que se façam algumas inferências. De forma esquemática, os sentidos do popular a partir do empírico contemporâneo estão associados a:

a) popular como estatuto ou como lugar: refere-se a pessoas de baixo poder aquisitivo, coisas de menor valor, preços baixos, ao sensacional, ao grotesco, à periferia; b) popular como atributo associado à humildade, alegria, simpatia, sociabilidade das pessoas; c) popular pelo uso: os lugares, objetos e acontecimentos freqüentados, utilizados e festejados pela maioria; d) popular associado à condição de pobreza, simplicidade, inferioridade, subalternidade; e) popular associado à raiz, à tradição cultural; f) popular como resistência política, enquanto classe, em oposição às classes hegemônicas; g) popular pelo idílico, pelo idealizado; h) popular por compromisso político ou por opção temática; i) popular pelo massivo ou pelas representações que faz o massivo do popular. Ao analisar os sentidos empíricos do popular chega-se à conclusão de que essa aparente polissemia pode

\footnotetext{
${ }^{9}$ Pequenas cidades da Região Metropolitana do Recife, Pernambuco.
} 
ser reduzida a dois sentidos: pessoas e coisas que são incluídas na categoria de popular; e aqueles que, pelas condições de origem política, econômica, social, educacional e laboral, estão fora dela. Em momento algum, dos depoimentos das categorias entrevistadas, aparecem os sentidos do popular em suas imbricações com a cultura massiva, a partir das quais se constroem as hibridizações, características das culturas globalizadas contemporâneas. A utilidade dessa compreensão segue na direção do sentido que defende García Canclini:

ayudar a discernir o que refuerza marginaciones arcaicas, las renueva o desafia. Sobre todo, para descubrir y compreender cómo pueden las culturas populares salir de su arriconamiento local y participar competitivamente, con sus creaciones y saberes, en los intercambios globales (García Canclini 2004: 86).

\section{REFERÊNCIAS BIBLIOGRÁFICAS}

ESCOSTEGUY, Ana Carolina D. Cartografias dos estudos culturais - uma versão latinoamericana. Belo Horizonte : Autêntica, 2001. GARCÍA CANCLINI, Néstor. Diferentes, desiguales y desconectados. Mapas da intercul-turalidad. Barcelona : Gedisa editorial, 2004. Latinoamericanos buscando lugar en este siglo.

$1^{\text {a }}$. Ed. Buenos Aires : Paidos, 2002.

- Culturas híbridas y estratégias comunicacionales. Semi-nário Fronteras culturales: Identidade y Comunicación en America Latina. Universidade de Stirling, outubro de 1996.

Consumidores e cidadãos: conflitos multiculturais da globalização. Rio de Janeiro : Ed. UFRJ, 1995.

. Culturas híbridas. Estratégias para entrar y salir de la modernidad. México :

Grijalbo, 1990.

. As culturas populares no Capitalismo. São Paulo : Brasili-ense, 1983.

. Ni folklorico, ni massivo : ¿ que es lo popular? Diálogos de la comunicación.

Lima : FELAFACS, Junho de 1987, n. 17.

. Cultura transnacional y culturas populares. Bases teórico-metodológicas para

la investigación, in: GARCÍA CANCLINI, Nestor e RONCAGLIOLO, Rafael (org.) Cultura transnacional y culturas populares. Lima : IPAL, 1988.

GONZALEZ, Jorge R. Sociologia das Culturas subalternas. Comala : Universidad Autônoma de Baja. Califórnia, 1990.

MARTIN-BARBERO, Jesus. Pre texto - conversaciones sobre la Comunicación y sus contextos. Cali : Centro Editorial Universidad Del Valle, 1995. 
Receptores imaginados: os sentidos do popular

de Maria Salett Tauk Santos

. Dos meios às mediações - comunicação, cultura e hegemonia. Rio de Janeiro :

Editora UFRJ, 1987.

TAUK SANTOS, M. Salett. O consumo de bens culturais nas culturas populares: identidade reconvertida ou diversidade refuncionalizada? In: Comunicação $e$ multicultu-ralismo (Org: Cicília M. K. Peruzzo e J. B. Pinho). São Paulo : Intercom, Manaus : UFAM, 2001.

Artigo recebido em 26/3/2009.

Aprovado em 5/5/2009. 